J. S. KIDD

\title{
On-Line Bibliographic Services: Selected British Experiences
}

\begin{abstract}
The British recently have completed a program to test and evaluate on-line bibliographic search capabilities at six of their institutions of higher education. Some of the insights derived from the test trials are relevant to U.S. academic librarians. Outcomes include high user appeal and the opportunity for new or expanded modes of service. The importance of advance planning regarding organizational adjustments, service promotion, and the specification of procedures for use of the new resources were made explicit by the test demonstrations.
\end{abstract}

$\mathrm{C}$

MONFRONTING THE AVAILABILITY of commercial on-line bibliographic search capabilities, the academic librarian sooner or later is forced to consider the following issues:

1. Whether to subscribe and which system or combination of systems to join;

2. Where to locate the operation in both a physical and an organizational sense;

3. How to promote and/or control user demand and access;

4. What procedures-of-use to establish.

These are not trivial issues. The advent of the capability to search computerized bibliographic files from remote stations could have subtle but

J. S. Kidd is acting dean, College of Library and Information Services, University of Maryland, College Park. The work reported here was subsidized in part by the Research and Development Department of the British Library by means of a consultancy arrangement. The author gratefully acknowledges the support provided by Dr. P. L. Holmes and his staff associates. However, the views represented are entirely those of the author and should in no way be considered as emanating from the British Library. profound effects on the ways in which college and university libraries are administered and how they are perceived by academic executives, faculty, and students.

One hint as to the nature of operational changes that might be induced by the presence of this relatively new mode of computer applications in libraries is manifested in the statistics which describe reference activities in annual reports. Characteristically, the number of "demand bibliographies" produced by the reference staff is very low. ${ }^{1}$

Insofar as formal, structured subject bibliographies are a tangible product of the reference process, they are generally produced by the user in a more or less intensively guided but primarily do-ityourself mode. The reference department provides the tools and the guidance but usually does not formulate the product, as such.

From some preliminary observations that will be presented in detail below, it seems more than likely that the modes of use of the computer capability can lead to a greatly increased output of individualized bibliographies that are formulated by a librarian rather than by the user (or by some other "agent," such as a graduate research assistant). 


\section{6 / College \& Research Libraries • July 1977}

One implication is that the whole conception of service productivity will change as a consequence. Other possibilities relate to the relative priority assigned to the continued expansion of holdings of certain reference materials. There are also staff training implications, etc. ${ }^{2}$ These concerns have emerged in a very short period of time. An early specification was made by Gardner and colleagues in $1974 .^{3}$ Their anticipation of these changes was only too valid.

In brief, one can safely assert that the availability of on-line search capabilities, while eminently attractive, is not likely to be an unalloyed blessing. There are likely to be certain problems incumbent upon the adoption of this innovation by academic librarians.

\section{BACKGROUND}

It is possible that the concerns expressed above, among others, prompted the responsible officials of the British Library Research and Development Division (BLRD) to institute a series of field trials as a form of pilot test and demonstration activity early in 1974 .

The broad, programmatic concern accorded to on-line bibliographic systems on the part of BLRD and the information professions at large in Britain has had many facets. It includes a range of activities from training librarians and others in the use of on-line equipment to the complete development of domestic (i.e., British) systems. Important precedents were laid down in the U.S.U.K. cooperative arrangements regarding the MEDLINE system which were refined in 1971 from the prior agreements established for MEDLARS in the 1960s.

Thus the observations which follow are reflective of only one modest component in a complicated array of activities relating to on-line bibliographic system development and evaluation. Specifically, the observations concern installations in environments in which engineering as a subject orientation was predominant. Moreover, and congruent with these settings, the systems under examination were limited to the Lockheed DIALOG system and the ORBIT system offered by the System Development Corporation.

\section{Trial Installations}

Six institutions of higher education participated in the pilot test project: the University of Manchester; the University of Wales-University College, Cardiff; the University of Edinburgh; Loughborough University; Hatfield Polytechnic; and Cranfield Institute of Technology. In the first three listed, the installation was operated either by a computer science department or (in the case of Edinburgh) by the computer service center. In the last three, the installation was operated by the library. There are other important differential aspects of setting, as follows.

The University of Manchester is an urban but residential institution in the industrial heartland. It is the major component in a central-city educational complex which includes the University of Manchester Institute of Science and Technology (essentially an autonomous body) and Manchester Polytechnic. This complex is geographically compact to the extent that it has been speculated that it provides one of the most dense concentrations of university-level faculty and students in Britain.

University College-Cardiff is similar except that the multi-institution "campus" is more extended in space.

The University of Edinburgh is urban, but the density factor is moderated somewhat by the recent provision of a branch campus (Kings) in a suburban location which now contains most of the science departments.

Loughborough University and Hatfield Polytechnic can be characterized as medium-sized, relatively new suburban facilities. Cranfield Institute is relatively small, restricted to graduatelevel instruction, and self-contained in a rural environment. 


\section{Observational Procedures}

In the late spring of 1975, informal site visits were undertaken at the behest of BLRD. The objective was to provide a marginal augmentation of the main mechanisms for evaluation in the form of an "uncommitted viewpoint."

For each installation, the main mechanisms for evaluation were the records initiated and maintained by the operational and managerial staff. The central but limited question to be resolved by means of on-site observations by an "outsider" was whether there were important situational factors that could affect the outcome of the evaluation but which might be taken for granted by the operational personnel because of their intense familiarity with their own environments.

In each case, the "outside observer" spent one day studying the situational factors. Interviews were conducted with the participating personnel, and a demonstration search was performed with the observer in the role of the user.

\section{Derivative Issues}

There were subtle situational factors that might moderate the main conclusions of the test trials. For example, the installation at Hatfield Polytechnic was located in the same area as an audiovisual instructional services unit. This arrangement brought the capability to the attention of a certain group of potential users who otherwise would have been only peripherally involved. Other issues came to light in the process of observation that seem more germane to academic librarianship in the U.S.

First and foremost, it was evident that the on-line search capability provides the base for new dimensions of service that can have strong user appeal. While in no instance was there an "overnight sensation" effect, demand grew over an eight- to ten-month span at an accelerating pace based mainly on wordof-mouth endorsements by users. The "classic" user was the graduate student in the early stages of a thesis or dissertation project. For these students and other users in a similar "project mode," the service was very welcome (i.e., "user acceptance" was high at all sites).

Second, it was apparent that the library base was superior to the computer science base. In minor part, this effect appears to result from the predilection of the computer science personnel to look upon the installation as a research tool as opposed to a service device. Perhaps more significantly, the library installations could complete the service process through the stage of document delivery whereas the computer sciencelinked installations could not.

Third, it became clear that the role of the "intermediary" in the service transaction was far more complicated and delicate than had been anticipated. In this context, the service transaction involves three entities: the user, the intermediary, and the terminal. The issue can be simplistically specified as the determination of an optimum level of participation by the intermediary in the user-system interaction at the terminal.

At one extreme, the intermediary plays a minor role in a quick initial introduction of user to terminal and acts thereafter as an on-demand technical consultant only when the user experiences some particular difficulty. At the other extreme, the intermediary acts as a user surrogate, with the user in the background or even absent during search operations. The first extreme is very inefficient, particularly for novice users. Since most users have only highly intermittent needs for demand bibliographies, novice status is not easily surpassed. The other extreme is ineffective in the same way that a batch-process search system is ineffective: real user interests are not always accurately translated into productive search strategies by the intermediary.

Tentative Recommendations

REgarding AdMinistrative Issues

To return to the explicit issues set 
out at the beginning, the question becomes that of whether the British experience provides either specific prescriptions or at least an approach to such prescriptions. Given the caveat that the experience in question is filtered through the perceptions of an "outsider," some recommendations can be made.

\section{The Decision to Subscribe}

The question of whether or not to subscribe can be answered affirmatively with the proviso that the most beneficial installations will be those in colleges and universities that have substantial research programs in the natural sciences or in engineering. Support capability for the social sciences and for professional programs (e.g., education, business administration, librarianship, etc.) remains spotty in spite of the availability of some relevant files such as Psychological Abstracts and ERIC. Support capability for the general humanities area is not yet significant. ${ }^{4}$

Even with such a proviso, the total constituency in the U.S. is in the range of 500 to 600 institutions, many of which should probably require more than one terminal. ${ }^{5}$ It has been estimated that only about thirty to forty such institutions have actually installed commercial system terminals in their main libraries at the time of this writing. ${ }^{6}$ (It should be noted that there are many more than thirty to forty university subscribers to the commercial on-line services. DIALOG alone has more than 200 such subscribers. ${ }^{7}$ The explanation of what would otherwise be unreconcilable data appears to be that most such subscriptions involve installations in computer science centers, special research units, or in branch libraries that serve a high-technology clientele.)

Cost is probably a factor in restraining the acceptance of commercial on-line services by academic library directors, given the present austere economic climate in higher education. Realistically, however, the capital costs are marginal for most large U.S. institutions, and operating costs are tied closely to the demand factor so that the usual ambiguities with respect to costeffectiveness are minimal.

The British experience is specifically instructive in this matter. While their austerity is significantly more intense than ours, ${ }^{8}$ the librarians' response was to retain their installations even though the subsidies which facilitated the test and demonstration program were about to be terminated. The head librarians interviewed expressed the intent to. confront their respective academic executives and argue vigorously for retention even if it meant some sacrifices in other budgetary areas. In some instances specific steps were taken to mobilize faculty support for such representations. ${ }^{9}$

\section{Location and Service Promotion}

The issues of location and service promotion are linked in an interesting way. The linkage is connoted in a negative manner by the proposition that it is easy enough to hide the capability and thus inhibit demand. Such a circumstance was aptly demonstrated by the installation in the computer science department at the University of Manchester. No imaginative U.S. librarian would have much difficulty in achieving the same outcome, if for some peculiar reason it was desired.

As indicated above, the dynamic upon which demand appears to depend is word-of-mouth promotion among faculty and students. In effect, a nucleus of satisfied customers spreads the word.

To expand somewhat, the British experience with promotional devices, such as printed announcements, was dismal. These usually cogent and articulate messages were either ignored or misinterpreted. A perhaps sociologically revealing misinterpretation that occurred at several sites was the erroneous belief that the service was limited to persons having faculty status.

Word-of-mouth dissemination has to 
have an initial trigger. This means that in some instances the librarian or other staff member has to take the initiative to identify individual prospective clients (e.g., students at a crucial stage in their thesis projects) and persuade them to try the system.

Word-of-mouth also has its own timelag pattern: the demand curve ultimately can become exponential, but the initial period always seems sluggish.

The need to be able to exert some control over demand growth is illustrated by the developments at Cranfield Institute of Technology. At the beginning of the academic year, demand was moderate, but enough clients were recruited to provide the trigger. Because of a relatively invariant activity sequence in their M.Sc. programs, the crucial stage of thesis planning occurred for a batch of 300 -plus students all at the same time, just after the turn of the year. This period happened to coincide with the natural acceleration of the demandgrowth curve. The service was limited to a capacity of two to three searches a day because of technicalities associated with the time differential between the U.K. and the U.S. Consequently, the service personnel experienced an acute overload situation during January and February and were forced to institute an advance-booking procedure. At one point, reservations were being made three weeks in advance. Moreover, because of activity deadlines, even the advance-booking procedure left some prospective users out. Although it was not documented as such, one suspects that the circumstances produced some attitudinal backlash.

It should be emphasized that there is no imputation here that the service was oversold. It was just that a combination of factors (including the relatively cohesive characteristic of the student body) generated a singular peak in the demand pattern.

The message for library management is clear: while a high level of demand, in effect, certifies the value of the service, some analytical effort is essential. Thus one can anticipate the pattern of demand growth and the rhythm of demand oscillations. Access procedures can be instituted to dampen the fluctuations and prevent any unfortunate whiplash effect from alternations between acute underuse and acute overload.

To return to the locational issue in the physical sense, the main admonition relates to convenience for both the users and the library staff. Ideally, the installation would have some perceptual prominence in the sense that library patrons could become aware of the resource in the natural course of other transactions. Such an arrangement would support the trigger process described above. On the contrary, the installation should be isolated from noise and movement distractions because considerable concentration is required for the effective use of the system. A good compromise might be a glass-walled space in the science reference area.

Such a prescription anticipates the issue of organizational location. Some affiliation with reference operations seems logical in light of the bibliographic nature of the service. However, there is at least one other important factor for administrators to consider, and that is document delivery. It is a characteristic of on-line systems to generate rather large bibliographies (e.g., 200-300 titles) from what appear to be relatively narrow searches. The user can be admonished to be selective in his or her requests for full-text materials but even so will often put the resources of even the best collections to a severe test.

The prescriptive inference from all this again seems clear: there must be an arrangement of close cooperation between the managers of the on-line service and the staff responsible for delivery to the user of full-text items. In most instances, such arrangements should include interlibrary loan and referral functions. 
The penalties for inadequate planning in this particular matter can be severe. Users can experience profound frustration if they are presented with their heart's desire in the form of an impressive list of patently relevant titles only to be told that some are unobtainable or obtainable only after a delay.

Another implication relates to the British experience regarding those installations not located in libraries. In such cases, the tenuous link between document identification and document delivery made the whole process of evaluation somewhat ambiguous. That is, users could express a high degree of satisfaction with the bibliographic search process and the product bibliography, but there was no easy way of knowing whether the ultimate outcome in terms of information acquisition was even moderately satisfactory. Those directly involved on the search side speculated openly that it probably often was not.

\section{Procedures of Use}

Finally, let us return briefly to the procedures-of-use issue. As suggested above, there are logical reasons to avoid the extremes of user participation in the on-line search process. This proposition implies that there might be an optimum middle ground. Indeed, the observer's personal preference is for a mode of use whereby the intermediary (librarian) operates the terminal and the user is present and can participate in the formulation and revision of the query and can observe the output. However, in all fairness the ideal arrangement is more probably one which is flexible. That is, the service should probably be able to accommodate the user who is sufficiently expert to operate the terminal in a completely do-it-yourself mode as well as the user who would prefer to delegate the search completely to the information professional.

Such a flexible procedure will require an adaptable and accommodating staff and a willingness to take the time to negotiate with each user as an individual. Though such individualized service is relatively costly, it is certainly within the accepted ideology of the profession.

\section{REFERENCES}

1. See, for example, R. B. Downs, "University of Illinois Library. Annual Report, 1970$71, "$ p. 7.

2. R. E. Hock, "Providing Access to Externally Available Bibliographic Data Bases in an Academic Library," College \& Research Libraries 36:208-15 (May 1975).

3. J. J. Gardner, D. Wax, and R. D. Morrison, Jr., "The Delivery of Computer-Based Bibliographic Search Services by Academic and Research Libraries," ARL Management Survey 2:1-6 (Sept. 1974).

4. Lockheed has announced the imminent availability of two new files, Historical $A b$ stracts and America: History and Life, which would appear to portend significant capability in the general humanities area.

5. This figure is based on an interpolated estimate from several statistical sources, including the listings of institutions designated class I and II-A made by the American As- sociation of University Professors (AAUP Bulletin 61:142 (Summer 1975)) and U.S. Office of Education statistics (S. V. Smith, Library Statistics of Colleges and Universities: Fall 1971: Analytic Report (Part C) (Washington: Govt. Print. Off., 1973).

6. Extrapolated from data presented in D. E. Williams, "Report to the Vice Chancellor for Academic Affairs on On-Line Literature Search Services" (College Park: McKeldin Library, University of Maryland, 1975).

7. R. K. Summit, personal communication, April 1976.

8. H. Perkin, "The Financial Crisis in British Universities: Or How to Live with 29 Percent Inflation," AAUP Bulletin 61:304-8 (Winter 1975).

9. J. S. Kidd, "Toward Cost-Effective Procedures in On-Line Bibliographic Searches," College \& Research Libraries 38:153-59 (March 1977). 